\title{
Flower pollination algorithm to solve dynamic economic loading of units with piecewise fuel options
}

\author{
Y V Krishna Reddy, M Damodar Reddy \\ Department of EEE, Sri Venkateswara College of Engineerining, Sri Venkateswara University, India
}

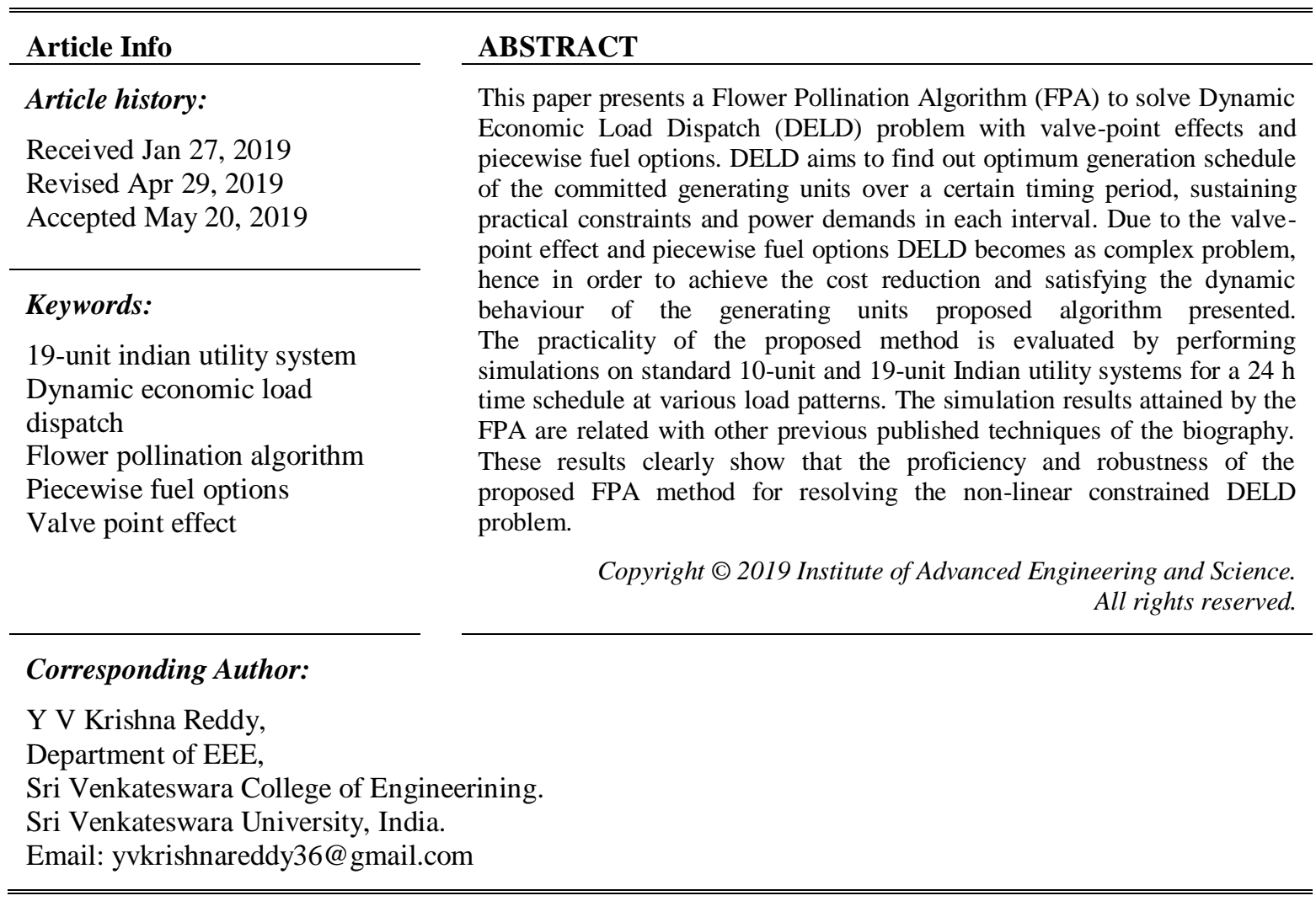

\section{INTRODUCTION}

Power system is a large complex system, Economic Load Dispatch (ELD) and Unit Commitment (UC) plays major role in order to reduce the cost to the consumers based on required load demand. In general, the cost functions of generator model by a quadratic function and later were solving the quadratic form by different methods. The quadratic form defined for the generator can be solved by different method like lambda iteration method, gradient-based method, dynamic programming etc. [1]. Usually these methods offer only the local optimum point and also require derivatives of the cost function of the generator.

To overcome these shortcomings, a lot of nature based optimization techniques have been applied of which the famous technique is Particle Swarm Optimization (PSO) [2]. However other approaches like Firefly algorithm (FFA) [3], Cuckoo Search Algorithm (CSA) [4] and Grey wolf optimization (GWO) [5] are also used to solve ELD problem. However, we can observe the discontinuities in the turbine-generator set performance characteristics, and those owe to valve-point (non-convex) loading in plants [1]. Hybrid approaches as modified Sub-Gradient (MSG) and Harmony Search Algorithms MSG-HS [6] and hybrid GA-NSO [7] methods are used for solving ELD with valve point effect (ELDVPE) problem.

Besides, instabilities occurring in the generation at some particular levels of unit loading may be caused by physical limitations or faults. This problem can be resolved by using the model known as prohibited operating zones (POZ) [1] and changes in the unit's generation level between any two simultaneous periods has not to be exceeded its ramp rate limits [1]. Backtracking search algorithm (BSA) 
[8], PSO [9] and Improved Random Drift PSO (RDPSO) [10] methods are used for solving ELD with ramp rate limits and POZs.

Present operating conditions of many thermal units, the generation cost functions for thermal plants be segmented as piecewise quadratic functions. Biogeography-based optimization (BBO) [11], Improved PSO [12], hybrid algorithm consisting of distributed sobol PSO, tabu search algorithm (DSPSO-TSA) [13], BSA [14] committed to the solve ELDVPE problem with multiple fuel options.

In practical power system Dynamic ELD (DELD) used to allocate the optimal generator outputs for a given various load demands in order to reduce the total operating cost over a given time period, imposed on practical constraints. DE algorithms have established attention in solving DELD problems [15, 16]. Other empirical search methods are Quantum GA (QGA) [17], Artificial Bee Colony (ABC) [18], PSO [19] and Multiple TS (MTS) [20] to solve DELD problems in the past decade. Hybrid methods such as hybrid AIS-SQP [21], and hybrid PSO-SQP [22] are found to be effective in solving complex DELD problem.

In this paper, to solve the DELD problem multiple fuel options proposed FPA method [23] implemented and simulation results are compared with refined DE algorithm [24]. FPA has shown good act in solving optimization problems in different areas, because only one key parameter p (switch probability) which makes the algorithm faster to reach global optimum solution. Moreover, this transferring switch between local and global pollination can guarantee escaping from local minimum solution. Results shown that FPA is capable to find better results comparing with other exploratory algorithms to solve DELD problem for test systems.

\section{DELD PROBLEM FORMULATION}

Explaining research chronological, including research design, research procedure (in the form of algorithms, Pseudocode or other), how to test and data acquisition [1-3]. The description of the course of research should be supported references, so the explanation can be accepted scientifically [2, 4].

The objectives function for DELD problem as follows:

$$
\operatorname{minTC}=\sum_{\mathrm{t}=1}^{\mathrm{T}} \sum_{\mathrm{i}=1}^{\mathrm{N}} \mathrm{C}_{\mathrm{it}}\left(\mathrm{P}_{\mathrm{it}}\right)
$$

Where $C_{i t}$ : Fuel cost of unit $\mathrm{i}$ at time $\mathrm{t}$ (in $\$ / \mathrm{h}$ ), N: Number of generation units, $\mathrm{P}_{\mathrm{it}}$ : Power output of $\mathrm{i}^{\text {th }}$ unit at time $\mathrm{t}$ (in MW), T: Total number of hours.

Due to involvement of valve-point the fuel cost of a generation unit defined as:

$$
\mathrm{C}_{\mathrm{it}}\left(\mathrm{P}_{\mathrm{it}}\right)=\mathrm{a}_{\mathrm{i}} \mathrm{P}_{\mathrm{it}}^{2}+\mathrm{b}_{\mathrm{i}} \mathrm{P}_{\mathrm{it}}+\mathrm{c}_{\mathrm{i}}+\left|\mathrm{e}_{\mathrm{i}} \sin \left(\mathrm{f}_{\mathrm{i}}\left(\mathrm{P}_{\mathrm{i}}^{\mathrm{min}}-\mathrm{P}_{\mathrm{it}}\right)\right)\right|
$$

Practically, the generating units are supplied with multiple fuels like oil, gas and coal. In general, the fuel cost represent as solitary quadratic function even though supplied with multiple fuels. For this purpose cost function represented as several piece-wise quadratic functions with valve-point effects,

$$
\mathrm{F}=\mathrm{F}_{\mathrm{C}}\left(\mathrm{P}_{\mathrm{Gk}}\right)=\left\{\begin{array}{lc}
\mathrm{a}_{\mathrm{k} 1} \mathrm{P}_{\mathrm{Gk}}^{2}+\mathrm{b}_{\mathrm{k} 1} \mathrm{P}_{\mathrm{Gk}}+\mathrm{c}_{\mathrm{k} 1}+\left|\mathrm{e}_{\mathrm{ck} 1} \times \sin \left(\mathrm{f}_{\mathrm{ck} 1} \times\left(\mathrm{P}_{\mathrm{Gk}}^{\min }-\mathrm{P}_{\mathrm{Gk}}\right)\right)\right| & \mathrm{P}_{\mathrm{Gk}}^{\min } \leq \mathrm{P}_{\mathrm{Gk}} \leq \mathrm{P}_{\mathrm{Gk} 1} \\
\mathrm{a}_{\mathrm{k} 2} \mathrm{P}_{\mathrm{Gk}}^{2}+\mathrm{b}_{\mathrm{k} 2} \mathrm{P}_{\mathrm{Gk}}+\mathrm{c}_{\mathrm{k} 2}+\left|\mathrm{e}_{\mathrm{ck} 2} \times \sin \left(\mathrm{f}_{\mathrm{ck} 2} \times\left(\mathrm{P}_{\mathrm{Gk}}^{\min }-\mathrm{P}_{\mathrm{Gk}}\right)\right)\right| & \mathrm{P}_{\mathrm{Gk} 1} \leq \mathrm{P}_{\mathrm{Gk}} \leq \mathrm{P}_{\mathrm{Gk} 2} \\
\mathrm{a}_{\mathrm{kn}} \mathrm{P}_{\mathrm{Gk}}^{2}+\mathrm{b}_{\mathrm{kn}} \mathrm{P}_{\mathrm{Gk}}+\mathrm{c}_{\mathrm{kn}}+\left|\mathrm{e}_{\mathrm{ckn}} \times \sin \left(\mathrm{f}_{\mathrm{ckn}} \times\left(\mathrm{P}_{\mathrm{G}}^{\min }-\mathrm{P}_{\mathrm{Gk}}\right)\right)\right| & \mathrm{P}_{\mathrm{Gk}(\mathrm{n}-1)} \leq \mathrm{P}_{\mathrm{Gk}} \leq \mathrm{P}_{\mathrm{Gk}}^{\max }
\end{array}\right.
$$

The DELD problem objective function maintain the following constraints should be minimized.

\subsection{Real Power Balance}

By considering network transmission losses, the equality constraint of the given network is written as:

$$
\sum_{i=1}^{N} P_{i t}=P_{D}(t)+P_{\text {loss }}(t) \quad t=1,2, \ldots . ., T
$$


Where $P_{\text {loss }}(t)$ : Total transmission loss of the system (in MW), $P_{D}(t)$ : Total power demand of the system at time $\mathrm{t}(\mathrm{MW})$. The power loss calculated using coefficients of the B matrix as follows:

$$
\mathrm{P}_{\text {loss }}(\mathrm{t})=\sum_{\mathrm{i}=1}^{\mathrm{N}} \sum_{\mathrm{j}=1}^{\mathrm{N}} \mathrm{P}_{\mathrm{it}} \mathrm{B}_{\mathrm{ij}} \mathrm{P}_{\mathrm{jt}} \quad \mathrm{t}=1,2,3, \ldots ., \mathrm{T}
$$

\subsection{Generation Limits of Units:}

$$
\mathrm{P}_{\mathrm{i}}^{\min } \leq \mathrm{P}_{\mathrm{it}} \leq \mathrm{P}_{\mathrm{i}}^{\max } \quad \mathrm{i}=1, \ldots \ldots, \mathrm{N}, \mathrm{t}=1,2, \ldots \ldots, \mathrm{T}
$$

Where $\mathrm{P}_{\mathrm{i}}^{\min }$ and $\mathrm{P}_{\mathrm{i}}^{\max }$ (in $\mathrm{MW}$ ) are the minimum, maximum power outputs of ith unit.

\subsection{Ramp Up and Ramp Down Constraints:}

The generation unit ramp rate limits are stated as follows:

$$
\begin{aligned}
& \mathrm{P}_{\text {it }}-\mathrm{P}_{\text {it }-1} \leq \mathrm{UR}_{\mathrm{i}} \quad \mathrm{i}=1, \ldots ., \mathrm{N}, \quad \mathrm{t}=1,2, \ldots ., \mathrm{T} \\
& \mathrm{P}_{\text {it }-1}-\mathrm{P}_{\text {it }} \leq \mathrm{DR}_{\mathrm{i}} \quad \mathrm{i}=1, \ldots \ldots, \mathrm{N}, \quad \mathrm{t}=1,2, \ldots ., \mathrm{T}
\end{aligned}
$$

Where $\mathrm{UR}_{\mathrm{i}}$ : Ramp up limit, $\mathrm{DR}_{\mathrm{i}}$ Ramp down limit of the $\mathrm{i}^{\text {th }}$ generator $(\mathrm{MW} / \mathrm{h})$. Due to involvement of ramp rate limits power limits can be modified as follows:

$$
\max \left(\mathrm{P}_{\mathrm{i}}^{\min }, \mathrm{P}_{\mathrm{it}-1}-\mathrm{DR}_{\mathrm{i}}\right) \leq \mathrm{P}_{\mathrm{it}} \leq \min \left(\mathrm{P}_{\mathrm{i}}^{\max }, \mathrm{P}_{\mathrm{it}-1}+\mathrm{UR}_{\mathrm{i}}\right) \mathrm{i}=1, \ldots . ., \mathrm{N}, \quad \mathrm{t}=1,2, \ldots . ., \mathrm{T}
$$

\subsection{Prohibited Operation Zone Limits (POZ):}

Due to stability concerns or limitations of machine components generating outputs have certain delimited operation zone. The generation unit acceptable operation zone canbe defined as:

$$
P_{i t} \in\left\{\begin{array}{l}
P_{i}^{\min } \leq P_{i t} \leq P_{i, 1}^{1} \\
P_{i, j-1}^{u} \leq P_{i t} \leq P_{i, j}^{1} \quad j=2,3, \ldots \ldots M_{i} \quad i=1, \ldots ., N \quad t=1,2, \ldots ., T \\
P_{i, M_{i}}^{u} \leq P_{i t} \leq P_{i}^{\max }
\end{array}\right.
$$

Where $P_{i, j}^{u}$ and $P_{i, j}^{l}$ are the upper and lower limits of the $j^{\text {th }}$ POZs of unit $i$, respectively. $M_{i}$ is the number of POZs of unit $i$.

\section{FLOWER POLLINATION ALGORITHM}

\subsection{Introduction}

In this section, new nature inspired optimization algorithm based on flower fertilization process has been proposed and implemented on DELD problem. Xin-She Yang developed FPA method in 2012. There are namely two types of fertilization processes known as biotic and abiotic. Majorly (90\%) the transfer of pollen occurs due to the biotic pollination by using pollinators as bats, birds, insects and other animals. Wind and diffusion help in the abiotic fertilization (10\% occur) rather than using pollinators.

Cross - fertilization or self - fertilization can achieve flower fertilization. First, one is due to the pollen fertilization of a different plant flower. Second, one occurs because one flower is fertilized from pollen of the same flower or other flowers of the same plant.

For FPA, the following four rules are used:

a) To find the global fittest, biotic and cross-fertilization considered, as pollen - carrying pollinators fly following Levy flights.

b) To find the local fittest, abiotic fertilization and Self-fertilization used.

c) Generally, insects can develop flower perseverance; this probability of reproduction is proportional to the similarity of the two flowers involved. 
d) The switch probability of $\mathrm{P} \varepsilon[0,1]$, is used to control interaction of local and global fertilization, which is slightly biased toward local pollinator.

\subsection{Mathematical Representation of FPA} as (11),

Global fittest $\left(\mathrm{g}_{*}\right)$ can be formulated using first rule, and it can be represented mathematically

$$
\mathrm{X}_{\mathrm{i}}^{\mathrm{t}+1}=\mathrm{X}_{\mathrm{i}}^{\mathrm{t}}+\mathrm{L}\left(\mathrm{X}_{\mathrm{i}}^{\mathrm{t}}-\mathrm{g}_{*}\right)
$$

Where $\mathrm{X}_{\mathrm{i}}^{\mathrm{t}}$ the solution is vector $\mathrm{X}_{\mathrm{i}}$ at iteration $\mathrm{t}$, and $\mathrm{g}_{*}$ is the current iteration best solution. L is the strength of fertilization should be greater than zero.

Levy distribution can be represent as (12)

$$
\mathrm{L} \approx \frac{\lambda \Gamma(\lambda)^{*} \sin (\pi \lambda / 2)}{\pi}\left(\frac{1}{\mathrm{~S}^{1+\lambda}}\right) \quad\left(\mathrm{S}>>\mathrm{S}_{0}>0\right)
$$

Where $\Gamma(\lambda)$ : Standard gamma function distribution is valid for large steps $S>0$.

For the local fertilization, both Rules 2 and 3 can be signified as shown in (13).

$$
\mathrm{X}_{\mathrm{i}}^{\mathrm{t}+1}=\mathrm{X}_{\mathrm{i}}^{\mathrm{t}}+\varepsilon\left(\mathrm{X}_{\mathrm{j}}^{\mathrm{t}}-\mathrm{X}_{\mathrm{k}}^{\mathrm{t}}\right)
$$

Here $\mathrm{X}_{\mathrm{j}}^{\mathrm{t}}$ and $\mathrm{X}_{\mathrm{k}}^{\mathrm{t}}$ are pollens from the different flowers of the same plant species. Here $\varepsilon_{\text {is drawn }}$ from a uniform distribution as $[0,1]$. In both local and global searches, flower pollination can occur. If there are two similar solutions, the search may be local; while there are two different solutions, the search will be global. The two parameters in this algorithm are population size $\mathrm{n}$ and probability switch (p [0, 1]). From our reproductions, found that probability switch $=0.75$ for solving DELD problem. The flower pollination algorithm to the solve DELD problem discussed in below. Implementation of Flower Pollination Algorithm:

Step 1: The algorithm begins by setting the initial population size (n), the switch probability (p), the maximum number of iterations, the search variables dimension (dim), the cost of generation coefficients, the B - matrix, the upper \& lower limit and the load demand for 24 hours.

Step2: Initialize the population or solutions of flower randomly.

Sol $(\mathrm{i},:)=\mathrm{Lb}+(\mathrm{Ub}-\mathrm{Lb}) . *$ rand $(1, \mathrm{dim})$.

Step3: Find the current best solution ${ }^{\mathrm{g}_{*}}$ in the initial population. $\left[\mathrm{F}_{\min }, \mathrm{I}\right]=\min$ (Fitness).

Step4: Start the iteration count $\mathrm{i}=1$.

Step5: Check the limits that are simple. If random is larger than p, use (11) to draw a step vector that obeys a levy distribution. Use (12) to make the global pollination.

Step6: Draw a uniform distribution in [ 0, 1 ] randomly select $\mathrm{j} \& \mathrm{k}$ among all solutions if random is less than $\mathrm{p}$. Use equation to do local pollination (13).

Step7: Check to see if all the restrictions are met if they are not met go to step 4. Assess new solutions (unit generation outputs, costs and losses).

Step8: Update the global fittest and its position.

Step9: Run the program up to meet the tolerance (0.00001). Display the results such as generation cost, power generations, transmission losses and total power generation for 24 hours.

\section{SIMULATION RESULTS}

The FPA method is examined on two test systems with ten and nineteen of units in this section. MATLAB programs are executed on a PC with 4 GB RAM using MATLAB R2014a to solve DELD issues with multiple fuel options. 30 Trails are considered in order to evaluate the robustness of the proposed FPA method for each system. The number of pollens in all test systems is 40 . The stop criteria are defined in this paper as reaching the tolerance of 0.00001. DELD problem is solved for three different load patterns, taking into account valve-point effects, losses and POZs, resulting in a non-convex quadratic programming problem. 


\subsection{Ten Unit Test System}

The 10-unit test system data are adapted from [24]. For this test system, valve-point loading, multiple fuel options and ramp rate limits are considered. The total time period of one day divided into 24 intervals, three various load patterns were considered. The peak demand for load pattern 1, pattern 2, and pattern 3 is $3208 \mathrm{MW}, 2460 \mathrm{MW}$, and $3210 \mathrm{MW}$, respectively. The obtained simulation results for this test system by proposed FPA method are presented in Table 1 for load pattern 2 . The fuel chosen by the units for all three load patterns is given in Table 2. The table format represents the fuel type chosen by a unit for pattern 1 and it is followed by fuel type for the same unit for patterns 2 and 3, respectively.

Table 1. Best Generation Dispatch Results Obtained by FPA for 10-Unit Test System for Load Pattern 2

\begin{tabular}{|c|c|c|c|c|c|c|c|c|c|c|}
\hline & $\mathrm{P} 1$ & $\mathrm{P} 2$ & P3 & $\mathrm{P} 4$ & P5 & P6 & P7 & P8 & P9 & P10 \\
\hline 1 & 142.6846 & 129.9651 & 200.0037 & 122.4141 & 190.0028 & 155.3210 & 200.0008 & 155.3207 & 257.2863 & 200.0008 \\
\hline 2 & 141.9089 & 129.8627 & 200.0143 & 156.3134 & 190.0396 & 152.8515 & 200.0009 & 120.0872 & 247.8791 & 200.0423 \\
\hline 3 & 140.3072 & 109.4027 & 200.0000 & 114.0102 & 190.0011 & 152.8468 & 200.0000 & 153.3417 & 250.0902 & 200.0000 \\
\hline 4 & 141.0976 & 180.2711 & 200.0003 & 117.1524 & 190.0004 & 154.8269 & 200.0000 & 116.0061 & 250.6439 & 200.0013 \\
\hline 5 & 163.2270 & 187.6980 & 213.1068 & 171.1580 & 190.2532 & 171.6529 & 200.0430 & 170.6631 & 282.1981 & 200.0000 \\
\hline 6 & 175.8724 & 194.3822 & 233.2710 & 227.8148 & 218.7790 & 227.4117 & 223.7101 & 227.8148 & 298.2520 & 209.6919 \\
\hline 7 & 168.7594 & 190.9163 & 218.1478 & 227.5460 & 194.2512 & 226.0680 & 216.4565 & 227.0086 & 292.7162 & 203.1300 \\
\hline 8 & 162.4357 & 187.7028 & 212.1101 & 170.1688 & 190.2016 & 169.6733 & 202.8615 & 171.1741 & 281.6410 & 200.0311 \\
\hline 9 & 137.9362 & 126.6959 & 200.0000 & 152.3520 & 190.0000 & 158.8366 & 200.0000 & 151.8571 & 247.3222 & 200.0000 \\
\hline 10 & 138.7410 & 178.2908 & 200.0011 & 110.2796 & 190.0019 & 111.0260 & 200.0439 & 152.8471 & 246.7687 & 200.0000 \\
\hline 11 & 164.8077 & 189.9261 & 215.1232 & 174.6222 & 190.0000 & 173.6324 & 204.7262 & 172.6426 & 285.5196 & 200.0000 \\
\hline 12 & 139.5188 & 108.9494 & 200.0001 & 154.8262 & 190.01710 & 152.3519 & 200.0083 & 153.3418 & 248.9817 & 200.0047 \\
\hline 13 & 166.3911 & 192.4020 & 219.1582 & 226.0683 & 193.8421 & 221.4993 & 204.8852 & 172.6440 & 284.9733 & 200.1365 \\
\hline 14 & 179.8241 & 198.3433 & 238.3121 & 229.5616 & 225.8503 & 228.3523 & 237.8363 & 232.5178 & 306.5558 & 218.8465 \\
\hline 15 & 201.1350 & 205.0275 & 263.5174 & 235.0708 & 247.8439 & 235.6083 & 259.2753 & 236.0114 & 325.9313 & 250.5791 \\
\hline 16 & 177.4531 & 195.8676 & 233.2710 & 228.6210 & 218.3949 & 229.8303 & 228.4522 & 228.0835 & 303.2343 & 215.7920 \\
\hline 17 & 166.3884 & 186.4602 & 215.1233 & 223.2462 & 190.4615 & 172.1477 & 204.7437 & 221.2306 & 282.1981 & 200.0003 \\
\hline 18 & 137.1460 & 123.5203 & 200.0001 & 152.8471 & 190.0000 & 110.8124 & 200.0000 & 152.3520 & 247.3222 & 200.0000 \\
\hline 19 & 154.5844 & 184.9748 & 205.0922 & 166.2073 & 190.1857 & 164.2556 & 200.0166 & 220.4241 & 272.2397 & 200.0198 \\
\hline 20 & 144.2780 & 178.0443 & 200.0014 & 121.5471 & 190.0042 & 120.3964 & 200.0378 & 154.8259 & 252.8569 & 200.0080 \\
\hline 21 & 144.2589 & 129.8678 & 200.0000 & 124.4969 & 190.0000 & 154.3315 & 200.0005 & 156.3112 & 256.7332 & 200.0000 \\
\hline 22 & 149.7913 & 181.0137 & 200.0000 & 161.7550 & 190.0769 & 160.7652 & 200.0000 & 159.7754 & 262.8226 & 200.0000 \\
\hline 23 & 141.0976 & 175.8149 & 200.0000 & 117.4415 & 190.0000 & 117.1274 & 200.0000 & 155.3213 & 251.1973 & 200.0000 \\
\hline 24 & 165.5980 & 191.1639 & 220.1643 & 175.6120 & 193.5260 & 174.6222 & 207.1130 & 174.1273 & 286.0732 & 200.0000 \\
\hline & & & & & & & & Total Cost & \multicolumn{2}{|c|}{$\$ 7880.0850$} \\
\hline
\end{tabular}

Table 2. Fuel Switching for Three Different Load Patterns to 10-unit Test System

\begin{tabular}{|c|c|c|c|c|c|c|c|c|c|c|}
\hline \multirow{2}{*}{ HOUR } & \multicolumn{10}{|c|}{ UNIT (MW) } \\
\hline & $\mathrm{P} 1$ & $\mathrm{P} 2$ & P3 & $\mathrm{P} 4$ & P5 & P6 & P7 & P8 & P9 & $\mathrm{P} 10$ \\
\hline 1 & $2,1,1$ & $1,2,1$ & $1,1,1$ & $3,2,3$ & $1,1,1$ & $3,1,1$ & $1,1,1$ & $3,2,2$ & $1,1,1$ & $1,1,1$ \\
\hline 2 & $2,1,1$ & $1,3,1$ & $1,1,1$ & $3,2,2$ & $1,1,1$ & $3,1,3$ & $1,1,1$ & $3,1,2$ & $1,1,1$ & $1,1,1$ \\
\hline 3 & $1,1,1$ & $1,3,1$ & $1,1,1$ & $2,2,2$ & $1,1,1$ & $1,2,1$ & $1,1,1$ & $2,2,2$ & $1,1,1$ & $1,1,1$ \\
\hline 4 & $1,1,1$ & $1,1,1$ & $1,1,1$ & $2,2,2$ & $1,1,1$ & $2,1,3$ & $1,1,1$ & $2,2,2$ & $1,1,1$ & $1,1,1$ \\
\hline 5 & $1,1,1$ & $1,1,1$ & $1,1,1$ & $2,2,2$ & $1,1,1$ & $1,1,3$ & $1,1,1$ & $2,3,3$ & $1,1,1$ & $1,1,1$ \\
\hline 6 & $1,1,2$ & $1,1,1$ & $1,1,1$ & $2,3,3$ & $1,1,1$ & $1,3,3$ & $1,1,1$ & $2,3,3$ & $1,1,3$ & $1,1,1$ \\
\hline 7 & $1,1,2$ & $1,1,1$ & $1,1,2$ & $2,3,3$ & $1,1,1$ & $3,3,3$ & $1,1,1$ & $3,2,3$ & $1,1,3$ & $1,1,1$ \\
\hline 8 & $1,1,2$ & $1,1,1$ & $1,1,2$ & $3,3,3$ & $1,1,1$ & $1,1,3$ & $1,1,2$ & $3,2,3$ & $1,1,3$ & $1,1,1$ \\
\hline 9 & $1,1,2$ & $1,3,1$ & $1,1,2$ & $3,2,3$ & $1,1,1$ & $3,1,3$ & $1,1,3$ & $3,2,3$ & $1,1,3$ & $1,1,1$ \\
\hline 10 & $1,1,2$ & $1,3,1$ & $1,1,2$ & $3,2,3$ & $1,1,1$ & $3,2,3$ & $1,1,1$ & $3,2,3$ & $3,1,3$ & $1,1,1$ \\
\hline 11 & $1,1,2$ & $1,1,1$ & $1,1,1$ & $3,2,3$ & $1,1,1$ & $3,3,3$ & $1,1,1$ & $3,2,3$ & $1,1,3$ & $1,1,1$ \\
\hline 12 & $1,1,2$ & $1,1,1$ & $1,1,1$ & $3,2,3$ & $1,1,1$ & $3,2,3$ & $1,1,1$ & $3,1,3$ & $1,1,3$ & $1,1,1$ \\
\hline 13 & $2,2,2$ & $1,1,1$ & $1,1,1$ & $3,3,3$ & $1,1,1$ & $3,3,3$ & 1,2 & $3,3,3$ & $3,3,1$ & $1,1,1$ \\
\hline 14 & $2,2,1$ & $1,1,1$ & $1,2,1$ & $3,3,2$ & $1,1,1$ & $3,3,1$ & $1,1,1$ & $3,3,2$ & $3,3,1$ & $1,1,1$ \\
\hline 15 & $2,2,1$ & $1,1,1$ & $1,1,1$ & $3,3,2$ & $1,1,1$ & $3,3,1$ & $1,1,1$ & $3,3,2$ & $3,1,1$ & $1,1,1$ \\
\hline 16 & $2,2,1$ & $1,1,1$ & $1,1,1$ & $3,3,2$ & $1,1,1$ & $3,3,3$ & $1,1,1$ & $3,3,3$ & $3,3,1$ & $1,1,1$ \\
\hline 17 & $2,2,1$ & $1,1,1$ & $2,1,1$ & $3,3,3$ & $1,1,1$ & $3,3,3$ & $2,1,1$ & $3,3,3$ & $3,3,1$ & $1,1,1$ \\
\hline 18 & $2,1,1$ & $1,3,1$ & $2,1,1$ & $3,2,3$ & $1,1,1$ & $3,1,3$ & $3,1,1$ & $3,1,3$ & $3,1,1$ & $1,1,1$ \\
\hline 19 & $2,1,2$ & $1,1,1$ & $1,1,1$ & $3,2,3$ & $1,1,1$ & $3,1,3$ & $1,1,1$ & $3,2,3$ & $3,1,3$ & $1,1,1$ \\
\hline 20 & $2,1,1$ & $1,3,1$ & $1,1,1$ & $3,2,3$ & $1,1,1$ & $3,1,3$ & $1,1,1$ & $3,1,3$ & $3,1,1$ & $1,1,1$ \\
\hline 21 & $2,1,2$ & $1,1,1$ & $1,1,1$ & $3,1,3$ & $1,1,1$ & $3,2,3$ & $1,1,1$ & $3,2,3$ & $3,1,1$ & $1,1,1$ \\
\hline 22 & $1,1,2$ & $1,1,1$ & $1,1,1$ & $3,2,3$ & $1,1,1$ & $1,1,3$ & $1,1,1$ & $3,2,3$ & $1,1,1$ & $1,1,1$ \\
\hline 23 & $1,1,1$ & $1,3,1$ & $1,1,1$ & $2,2,3$ & $1,1,1$ & $1,1,3$ & $1,1,1$ & $2,3,3$ & $1,1,1$ & $1,1,1$ \\
\hline 24 & $1,1,1$ & $1,1,1$ & $1,1,1$ & $1,2,2$ & $1,1,1$ & $2,1,3$ & $1,1,1$ & $2,2,2$ & $1,1,1$ & $1,1,1$ \\
\hline
\end{tabular}


The best cost obtained by the FPA method for pattern 1, 2, and 3 is $\$ 9526.2580,7788.1972$, and $\$ 10276.8797$, respectively. The worst cost for pattern 1 is $\$ 9550.6938$, pattern 2 is $\$ 7821.2645$, and pattern 3 is $\$ 10311.2545$. The average cost for pattern 1 is 9535.9478, pattern 2 is $\$ 7821.2645$, and pattern 3 is $\$ 10311.2545$. These results are compared with DE-NM [24] method presented in recent literature in terms of minimum cost, mean cost, and maximum cost over 30 runs those are presented in Table 3. By investigating the results presented in Table 3, it can be observed that the obtained results outperform the DE-NM method for 10-unit test system.

Table 3. Comparison Results of Different Load Patterns for 10-Unit Test System

\begin{tabular}{ccccc}
\hline Load demand & Method & Minimum Cost $(\$)$ & Average Cost $(\$)$ & Maximum Cost (\$) \\
\hline \multirow{2}{*}{ Pattern 1 } & DE-NM [24] & 10649.68 & 11451.82 & 11952.07 \\
& Proposed FPA & $\mathbf{9 5 2 6 . 2 5 8 0}$ & 9535.9478 & 9550.6938 \\
Pattern 2 & DE-NM [24] & 8103.326 & 9711.448 & 9163.973 \\
& Proposed FPA & $\mathbf{7 7 8 8 . 1 9 7 2}$ & 7800.8958 & 7821.2645 \\
Pattern 3 & DE-NM [24] & 11054.83 & 11497.85 & 12036.89 \\
& Proposed FPA & $\mathbf{1 0 2 7 6 . 8 7 9 7}$ & 10293.2937 & 10311.2545 \\
\hline
\end{tabular}

\subsection{9-unit Indian Utility Test System}

This system involves a standard Indian utility system with 19 units. All the 19 units include nonlinear characteristics such as valve point effect, ramp rate limit, multiple fuels, prohibited operating zones and spinning reserve constraint. This system is applied for three different load patterns. The maximum demand for pattern 1 is $4400 \mathrm{MW}$, for pattern 2 is $4186 \mathrm{MW}$, and for pattern 3 is $4173 \mathrm{MW}$. Table 4 gives the best generation schedule obtained by the FPA method for pattern 2. Few units in the system are provided with multiple fuel option. The fuel types include 1, 2, 3, 4, 5and 6. Table 5 shows the fuel switching for units $3,5,7,13$, and 19 and all the remaining units utilize fuel 1 for every hour of time interval.

Table 4. Best Generation Dispatch Results Obtained by FPA for 19-unit Indian Utility System for Load Pattern 2

\begin{tabular}{|c|c|c|c|c|c|c|c|c|c|c|}
\hline & P1 & $\mathrm{P} 2$ & P3 & $\mathrm{P} 4$ & P5 & P6 & P7 & P8 & P9 & $\mathrm{P} 10$ \\
\hline 1 & 100.0000 & 120.0327 & 100.9887 & 20.76666 & 82.2480 & 161.8143 & 175.9278 & 100.0009 & 200.1628 & 33.3400 \\
\hline 2 & 100.0002 & 123.2428 & 100.6766 & 17.0406 & 176.5358 & 150.1571 & 176.5470 & 100.1397 & 200.7483 & 30.3581 \\
\hline 3 & 112.4216 & 121.6729 & 249.9994 & 15.3482 & 174.3989 & 230.7346 & 171.0398 & 100.3583 & 212.7103 & 31.4505 \\
\hline 4 & 100.0118 & 371.7785 & 345.5735 & 8.3328 & 176.1724 & 217.9259 & 175.7711 & 112.1717 & 202.8636 & 39.9983 \\
\hline 5 & 100.0015 & 432.6571 & 378.4861 & 10.3150 & 175.0199 & 294.9874 & 176.5728 & 100.0164 & 204.5333 & 39.9479 \\
\hline 6 & 139.2736 & 433.5937 & 399.9891 & 25.0000 & 176.1002 & 398.4731 & 169.8704 & 233.0472 & 200.0488 & 39.9888 \\
\hline 7 & 240.9011 & 435.9810 & 396.2001 & 23.9839 & 176.5697 & 299.9995 & 176.5505 & 427.6827 & 353.8093 & 27.3263 \\
\hline 8 & 248.3570 & 437.9769 & 399.9811 & 22.2722 & 176.5247 & 395.1113 & 176.5009 & 402.1547 & 389.2728 & 39.8374 \\
\hline 9 & 100.0028 & 120.0428 & 356.4301 & 10.3553 & 174.8167 & 220.9792 & 176.6223 & 100.0000 & 200.1354 & 32.2547 \\
\hline 10 & 100.0035 & 245.8055 & 249.9997 & 23.7589 & 175.2543 & 184.3788 & 176.3841 & 124.1856 & 204.9449 & 17.3496 \\
\hline 11 & 110.0156 & 179.5462 & 249.9990 & 20.6745 & 168.9997 & 151.6498 & 81.9179 & 100.5506 & 201.8712 & 20.8552 \\
\hline 12 & 100.0752 & 182.5495 & 251.9955 & 8.0030 & 172.7171 & 166.7121 & 175.7966 & 100.0467 & 200.0000 & 38.7754 \\
\hline 13 & 100.0022 & 120.4559 & 110.1985 & 12.0364 & 80.6498 & 150.0289 & 176.5759 & 100.0413 & 200.2619 & 17.5664 \\
\hline 14 & 100.0002 & 120.3974 & 150.9720 & 24.5498 & 82.8460 & 150.0019 & 82.8728 & 100.0004 & 200.3569 & 35.3499 \\
\hline 15 & 100.0008 & 120.4163 & 137.5633 & 21.2887 & 175.5058 & 160.0827 & 175.5111 & 100.0010 & 200.3982 & 39.9262 \\
\hline 16 & 101.4075 & 307.0646 & 249.9996 & 24.9200 & 175.5223 & 342.2286 & 169.6239 & 100.7939 & 205.7584 & 19.8109 \\
\hline 17 & 108.7141 & 308.5629 & 386.2323 & 24.9878 & 170.3976 & 246.2583 & 173.5649 & 100.2903 & 200.0000 & 39.9939 \\
\hline 18 & 100.0207 & 183.1580 & 320.3185 & 12.2250 & 176.1875 & 155.0934 & 176.2270 & 130.1912 & 200.0448 & 33.9815 \\
\hline 19 & 100.0054 & 244.7331 & 249.9994 & 24.9671 & 176.5464 & 166.0365 & 176.4829 & 100.0276 & 200.6785 & 16.0514 \\
\hline 20 & 100.0000 & 183.1689 & 170.9149 & 23.7713 & 174.9614 & 190.8759 & 168.4022 & 100.0141 & 230.4055 & 18.3130 \\
\hline 21 & 100.0003 & 120.0003 & 100.1160 & 24.9015 & 176.6244 & 150.9495 & 176.6234 & 100.0025 & 200.0613 & 15.5214 \\
\hline 22 & 100.0000 & 120.0082 & 100.0068 & 19.1080 & 168.3374 & 150.0045 & 176.6190 & 100.0028 & 200.0003 & 15.3447 \\
\hline 23 & 100.0000 & 120.0377 & 100.0003 & 24.7610 & 176.3491 & 150.1893 & 74.5563 & 100.0037 & 200.6072 & 32.2142 \\
\hline 24 & 100.0009 & 120.0838 & 120.0493 & 23.1896 & 175.7491 & 150.2228 & 82.2767 & 100.0029 & 200.0077 & 15.0114 \\
\hline
\end{tabular}

\begin{tabular}{ccccccccccc}
\hline & P11 & P12 & P13 & P14 & P15 & P16 & P17 & P18 & P19 & COST $(\$ / h)$ \\
\hline 1 & 132.3604 & 73.1954 & 176.5942 & 74.1227 & 20.0078 & 78.0941 & 78.1721 & 75.1541 & 400.0176 & 10609.8946 \\
2 & 87.2892 & 65.6923 & 67.4513 & 87.6610 & 20.0000 & 73.2831 & 26.8840 & 87.2291 & 400.0640 & 10418.9046 \\
3 & 139.2190 & 56.6975 & 62.5055 & 90.0000 & 49.2406 & 79.9796 & 78.9417 & 227.2816 & 400.0000 & 11687.5017 \\
4 & 149.6111 & 74.8889 & 176.1803 & 89.5715 & 74.4076 & 77.6175 & 79.9984 & 228.9912 & 400.1341 & 14987.5124 \\
5 & 149.8977 & 74.8782 & 176.6218 & 89.8920 & 212.6962 & 78.1103 & 80.0000 & 229.3269 & 400.0394 & 17174.8152 \\
6 & 149.9886 & 74.9744 & 176.3482 & 89.9768 & 212.7035 & 78.2667 & 79.9569 & 229.63 & 400.7634 & 19939.2191 \\
7 & 149.7958 & 67.6665 & 176.6001 & 89.9991 & 216.9499 & 78.9131 & 79.9998 & 224.9247 & 467.1469 & 22687.3545 \\
8 & 149.9985 & 74.9136 & 176.5884 & 89.9880 & 216.8708 & 79.9707 & 79.8060 & 229.8747 & 400.0000 & 25033.9678 \\
\hline
\end{tabular}

Indonesian J Elec Eng \& Comp Sci, Vol. 16, No. 1, October 2019 : 9 - 16 


\begin{tabular}{|c|c|c|c|c|c|c|c|c|c|c|}
\hline & P11 & $\mathrm{P} 12$ & P13 & P14 & P15 & P16 & $\mathrm{P} 17$ & P18 & P19 & $\operatorname{COST}(\$ / h)$ \\
\hline 9 & 149.6243 & 71.8199 & 169.7801 & 90.0000 & 158.2310 & 77.6133 & 79.9546 & 229.9224 & 400.4152 & 13756.5375 \\
\hline 10 & 140.3102 & 74.7562 & 175.9684 & 86.4321 & 28.4338 & 74.5815 & 79.9455 & 228.3214 & 400.1859 & 11697.5801 \\
\hline 11 & 150.0000 & 25.0000 & 175.9665 & 89.4232 & 49.3258 & 80.0000 & 80.0000 & 229.9464 & 400.2582 & 10962.9719 \\
\hline 12 & 67.1626 & 72.5701 & 173.8985 & 90.0000 & 20.0000 & 24.9347 & 79.4158 & 170.8804 & 400.4669 & 11748.6299 \\
\hline 13 & 83.2022 & 65.3406 & 176.1549 & 12.5828 & 53.5100 & 79.5802 & 77.6139 & 229.1548 & 400.0435 & 10864.6588 \\
\hline 14 & 149.9959 & 71.1066 & 176.5922 & 89.9758 & 20.0033 & 79.9925 & 79.8423 & 229.9849 & 400.1594 & 11380.2207 \\
\hline 15 & 149.7868 & 74.9990 & 172.3164 & 88.3079 & 166.6085 & 79.9998 & 80.0000 & 229.6210 & 401.6666 & 12276.2114 \\
\hline 16 & 124.7012 & 69.4550 & 176.0328 & 54.4291 & 193.7624 & 72.8755 & 79.6993 & 216.6866 & 406.2283 & 14492.9218 \\
\hline 17 & 149.9914 & 75.0000 & 174.9108 & 88.9011 & 166.6066 & 73.9374 & 79.8305 & 229.8168 & 400.0033 & 15564.6556 \\
\hline 18 & 149.8850 & 72.0212 & 175.9815 & 89.3313 & 200.1121 & 79.9347 & 79.9764 & 211.4989 & 400.8112 & 13903.0686 \\
\hline 19 & 149.9887 & 72.7335 & 176.6089 & 89.9573 & 57.7103 & 80.0000 & 79.9946 & 229.3496 & 400.1288 & 11544.5647 \\
\hline 20 & 50.1422 & 73.8478 & 173.9423 & 75.2285 & 103.7723 & 31.5194 & 78.7547 & 154.9686 & 400.0000 & 12138.0264 \\
\hline 21 & 70.3626 & 74.9741 & 175.5616 & 61.8712 & 20.0027 & 72.0377 & 79.8549 & 85.5340 & 400.0006 & 10275.9358 \\
\hline 22 & 79.1162 & 48.0748 & 176.4270 & 8.6713 & 20.0001 & 79.9986 & 50.8617 & 165.4000 & 400.0186 & 10327.0054 \\
\hline 23 & 131.1185 & 42.8497 & 176.5582 & 71.4559 & 20.0012 & 79.8770 & 31.4897 & 72.9299 & 401.0009 & 10422.7257 \\
\hline 24 & 101.3351 & 38.7833 & 176.5711 & 87.1548 & 24.1851 & 75.8279 & 79.2886 & 148.1634 & 400.0965 & 10529.4970 \\
\hline & & & & & & & & Total Cost & \multicolumn{2}{|c|}{$\$ 324424.3813$} \\
\hline
\end{tabular}

Table 5. Fuel Switching for Three Different Load Patterns to 19-unit Indian Utility System

\begin{tabular}{ccccccc}
\hline \multirow{2}{*}{ HOUR } & & \multicolumn{5}{c}{ UNIT $(\mathrm{MW})$} \\
& P3 & P5 & P6 & P7 & P13 & P19 \\
\hline 1 & $1,1,2$ & $6,5,6$ & $2,2,1$ & $6,6,6$ & $6,6.6$ & $1,1,1$ \\
3 & $1,1,2$ & $5,6,6$ & $2,2,2$ & $6,6,6$ & $6,5,6$ & $1,1,1$ \\
4 & $1,1,2$ & $6,6,6$ & $2,2,2$ & $6,6,6$ & $6,3,6$ & $1,1,1$ \\
5 & $1,2,2$ & $6,6,5$ & $2,2,2$ & $6,6,6$ & $6,6,6$ & $1,1,1$ \\
6 & $2,2,2$ & $5,6,6$ & $2,2,2$ & $6,6,6$ & $6,6,6$ & $1,1,1$ \\
7 & $2,2,2$ & $6,6,6$ & $2,1,6$ & $6,6,6$ & $6,6,6$ & $1,1,1$ \\
8 & $2,2,2$ & $6,6,6$ & $2,6,1$ & $6,1,6$ & $6,6,6$ & $1,1,1$ \\
9 & $2,2,2$ & $6,6,6$ & $6,1,2$ & $1,6,6$ & $6,6,6$ & $1,1,1$ \\
10 & $2,2,2$ & $6,6,6$ & $2,2,2$ & $6,6,6$ & $6,6,6$ & $1,1,1$ \\
11 & $2,1,2$ & $6,6,6$ & $6,2,2$ & $1,6,5$ & $6,6,6$ & $1,1,1$ \\
12 & $2,1,2$ & $6,6,6$ & $1,2,2$ & $6,5,6$ & $6,6,6$ & $2,1,1$ \\
13 & $2,2,2$ & $6,6,6$ & $1,2,2$ & $6,6,6$ & $6,6,6$ & $1,1,1$ \\
14 & $2,1,1$ & $6,5,6$ & $6,2,2$ & $1,6,6$ & $6,6,6$ & $1,1,1$ \\
15 & $2,1,1$ & $6,5,6$ & $6,2,2$ & $1,5,6$ & $6,6,6$ & $1,1,1$ \\
16 & $2,1,1$ & $6,6,6$ & $2,1,2$ & $6,6,5$ & $6,6,5$ & $1,1,1$ \\
17 & $2,2,1$ & $6,6,6$ & $6,2,2$ & $1,6,6$ & $6,6,6$ & $1,1,1$ \\
18 & $2,2,1$ & $6,6,6$ & $6,2,2$ & $1,6,6$ & $6,6,6$ & $1,1,1$ \\
19 & $2,1,2$ & $6,6,6$ & $6,2,2$ & $1,6,6$ & $6,6,6$ & $1,1,1$ \\
20 & $1,1,2$ & $6,2,6$ & $2,6,2$ & $6,6,6$ & $6,6,6$ & $1,1,1$ \\
21 & $2,1,2$ & $6,6,6$ & $2,2,2$ & $6,6,6$ & $6,6,6$ & $1,1,1$ \\
22 & $1,1,2$ & $6,6,6$ & $2,2,6$ & $6,6,1$ & $6,6,6$ & $1,1,1$ \\
23 & $2,1,2$ & $6,6,6$ & $2,2,2$ & $5,5,6$ & $6,6,6$ & $1,1,1$ \\
24 & $1,1,2$ & $6,6,6$ & $2,2,6$ & $5,5,1$ & $6,6,6$ & $1,1,1$ \\
\hline
\end{tabular}

The best cost obtained by the FPA method for pattern 1,2 , and 3 is $\$ 379594.8892,324424.3813$, and $\$ 358242.0471$, respectively. Te worst cost for pattern 1 is $\$ 386008.3299$, pattern 2 is $\$ 330761.8204$, and pattern 3 is $\$ 367925.4131$. The average cost for pattern 1 is 383482.8741 , pattern 2 is $\$ 326958.9964$, and pattern 3 is $\$ 364261.6592$. These results are compared with DE-NM method presented in recent literature in terms of minimum cost, mean cost, and maximum cost over 30 runs those are presented in Table 6. By investigating the results presented in Table 6, it can be observed that the obtained results outperform the DE-NM method for 19-unit test system.

Table 6. Comparison Results of Different Load Patterns for 19-unit Indian Utility Test System

\begin{tabular}{ccccc}
\hline Load demand & Method & Minimum Cost $(\$)$ & Average Cost $(\$)$ & Maximum Cost (\$) \\
\hline Pattern 1 & DE-NM [24] & 404122.623 & 405515.7524 & 405665.6592 \\
& Proposed FPA & $\mathbf{3 7 9 5 9 4 . 8 8 9 2}$ & 383482.8741 & 386008.3299 \\
Pattern 2 & DE-NM [24] & 324962.343 & 334321.1071 & 341440.818 \\
& Proposed FPA & $\mathbf{3 2 4 4 2 4 . 3 8 1 3}$ & 326958.9964 & 330761.8204 \\
Pattern 3 & DE-NM [24] & 372140.528 & 33109.9977 & 374405.694 \\
& Proposed FPA & $\mathbf{3 5 8 2 4 2 . 0 4 7 1}$ & 364261.6592 & 367925.4131 \\
\hline
\end{tabular}




\section{CONCLUSION}

In this paper, the Flower Pollination Algorithm (FPA) is used to solve the DELD problem, including ramp rate effects, prohibited operating zones and multiple fuel options within a single frame. With ten and19unit Indian utility test systems for different load patterns for 24-hour time interval, the feasibility of the proposed method was demonstrated. The test results show that the optimal dispatch solution obtained by the proposed FPA method is superior to other methods presented in the literature to determine the optimal solution to solve the DELD problem. The proposed approach outperforms the method used by DE - NM to solve DELD problems with better performance in terms of solution quality.

\section{REFERENCES}

[1] Weerakorn, "Artificial intelligence in power system optimization", CRC press, Taylor and Francis group, 2013.

[2] Hardiansyah, Junaidi. "Solving Economic Load Dispatch problem using particle swarm Optimization Technique", I.J. Intelligent Systems and Applications, 2012, 12, 12-18.

[3] K. Sudhakara Reddy, Dr. M. Damodar Reddy. "Economic Load Dispatch Using Firefly Algorithm”, IJERA, Vol. 2, Issue4, July-August 2012, pp.2325-30.

[4] A.Hima Bindu, Dr. M. Damodar Reddy, "Economic Load Dispatch Using Cuckoo Search Algorithm", IJERA, Vol. 3, Issue 4, Jul-Aug 2013, pp. 498-502.

[5] Dr.Sudhir Sharma,Shivani Mehta "Economic Load Dispatch Using Grey Wolf Optimization", IJERA, Vol. 5, Issue 4, ( Part -6) April 2015, pp.128-132.

[6] Celal Yas, "A new hybrid approach for nonconvex EDP with valve-point effect", Energy. 36 (2011) 5838-45.

[7] Tahir Nadeem Malik, Azzam ul Asar "A new hybrid approach for the solution of nonconvex ED problem with valve-point effects", Electric Power Systems Research 80 (2010) 1128-1136.

[8] Mostafa Modiri-Delshad, "Backtracking search algorithm for solving economic diapatch problems with valve-point effects and multiple fuel optins", Energy 116 (2016) 637e649.

[9] Zwe-Lee Gaing "Particle Swarm Optimization to Solving the economic dispatch considering the generator constrints", IEEE transactions on power systems, vol. 18, no. 3, august 2003.

[10] Wael Taha Elsayed, Yasser G. Hegazy "Improved Random Drift Particle Swarm Optimization With Self-Adaptive Mechanism for Solving the Power Economic Dispatch Problem”, IEEE transactions on industrial informatics, vol. 13, no. 3, june 2017.

[11] Aniruddha Bhattacharya and Pranab Kumar Chattopadhyay. May 2010, "Biogeography-Based Optimization for Different Economic Load Dispatch Problems" IEEE Transactions on Power Systems, Vol. 25, No. 2.

[12] Jong-Bae Park, Yun-Won Jeong, Joong-Rin Shin. Feb 2010, “An Improved Particle Swarm Optimization for Nonconvex Economic Dispatch Problems” IEEE Transactions on Power Systems, Vol. 25, No. 1.

[13] S. Khamsawang, S. Jiriwibhakorn. 2010, "DSPSO-TSA for economic dispatch problem with nonsmooth and noncontinuous cost functions" Energy Conversion and Management 51 365-375.

[14] Mostafa Modiri-Delshad, S. Hr. Aghay Kaboli. "Backtracking search algorithm for solving economic dispatch problems with valve-point effects and multiple fuel options" Energy 116 (2016) 637e649.

[15] R. Balamurugan, S. Subramanian, "Differential Evolution-based Dynamic Economic Dispatch of Generating Units with Valve-point Effects" Electric Power Components and Systems, 36:828-843, 2008.

[16] Xiaohui Yuan, Liang Wang, Yanbin Yuan, "A modified differential evolution approach for dynamic economic dispatch with valve-point effects”, Energy Conversion and Management 49 (2008) 3447-3453.

[17] Jia-Chu Lee, Whei-Min Lin, Gwo-Ching Liao, "Quantum genetic algorithm for dynamic economic dispatch with valve-point effects and including wind power system", Electrical Power and Energy Systems 33 (2011) 189-197.

[18] S. Hemamalini and Sishaj P. Simon, "Dynamic economic dispatch using artificial bee colony algorithm for units with valve-point effect" Euro. Trans. Electr. Power 2011; 21:70-81.

[19] B.K. Panigrahi, V. Ravikumar Pandi, Sanjoy Das, "Adaptive particle swarm optimization approach for static and dynamic economic load dispatch" Energy conservation and management 49 (2008) 1407-1415.

[20] Saravuth Pothiya, Issarachai Ngamroo, "Application of multiple tabu search algorithm to solve dynamic economic dispatch considering generator constraints" Energy Conversion and Management 49 (2008) 506-516.

[21] M. Basu, "Hybridization of Artificial Immune Systems and Sequential Quadratic Programming for Dynamic Economic Dispatch", Electric Power Components and Systems, 37:1036-1045, 2009.

[22] T. Aruldoss Albert Victoire, A. Ebenezer Jeyakumar, "Reserve Constrained Dynamic Dispatch of Units With Valve-Point Effects", IEEE transactions on power systems, vol. 20, no. 3, august 2005.

[23] Xin-She Yang "Flower Pollination Algorithm for Global Optimization", Soft Computing Tech. 2014.

[24] J. Jasper and T. Aruldoss, "Dispatching a 19-Unit Indian Utility System Using a Refined Differential Evolution Algorithm" Hindawi Publishing Corporation Mathematical Problems in Engineering Volume 2014. 